- Original Paper •

\title{
Evaluation of Unified Model Microphysics in High-resolution NWP Simulations Using Polarimetric Radar Observations
}

\author{
Marcus JOHNSON ${ }^{1,2}$, Youngsun JUNG ${ }^{* 1,2}$, Daniel DAWSON ${ }^{3}$, Timothy SUPINIE ${ }^{1,2}$, \\ Ming XUE ${ }^{1,2}$, Jongsook PARK ${ }^{4}$, and Yong-Hee LEE ${ }^{4}$ \\ ${ }^{1}$ Center for Analysis and Prediction of Storms (CAPS), University of Oklahoma, Norman, OK 73072, USA \\ ${ }^{2}$ School of Meteorology, University of Oklahoma, Norman, OK 73072, USA \\ ${ }^{3}$ Purdue University, West Lafayette, IN 47907, USA \\ ${ }^{4}$ Korea Meteorological Administration, Seoul 07062, Korea
}

(Received 20 July 2017; revised 20 December 2017; accepted 27 December 2017)

\begin{abstract}
The UK Met Office Unified Model (UM) is employed by many weather forecasting agencies around the globe. This model is designed to run across spatial and time scales and known to produce skillful predictions for large-scale weather systems. However, the model has only recently begun running operationally at horizontal grid spacings of $\sim 1.5 \mathrm{~km}[\mathrm{e} . \mathrm{g}$., at the UK Met Office and the Korea Meteorological Administration (KMA)]. As its microphysics scheme was originally designed and tuned for large-scale precipitation systems, we investigate the performance of UM microphysics to determine potential inherent biases or weaknesses. Two rainfall cases from the KMA forecasting system are considered in this study: a Changma (quasi-stationary) front, and Typhoon Sanba (2012). The UM output is compared to polarimetric radar observations in terms of simulated polarimetric radar variables. Results show that the UM generally underpredicts median reflectivity in stratiform rain, producing high reflectivity cores and precipitation gaps between them. This is partially due to the diagnostic rain intercept parameter formulation used in the one-moment microphysics scheme. Model drop size is generally both underand overpredicted compared to observations. UM frozen hydrometeors favor generic ice (crystals and snow) rather than graupel, which is reasonable for Changma and typhoon cases. The model performed best with the typhoon case in terms of simulated precipitation coverage.
\end{abstract}

Key words: Unified Model, microphysics, polarimetric radar, radar simulator, numerical weather prediction

Citation: Johnson, M., Y. Jung, D. Dawson, T. Supinie, M. Xue, J. Park, and Y.-H. Lee, 2018: Evaluation of Unified Model microphysics in high-resolution NWP simulations using polarimetric radar observations. Adv. Atmos. Sci., 35(7), 771-784, https://doi.org/10.1007/s00376-017-7177-0.

\section{Introduction}

As computing power consistently increases, operational centers run numerical weather prediction (NWP) models with convective-scale ( $\leqslant 4 \mathrm{~km}$; Weisman et al., 1997) grid spacing (e.g., Tang et al., 2013; Goldenberg et al., 2015; Kim, 2015; Park et al., 2015a; Ballard et al., 2016). Model microphysical processes become significant at this resolution and drive the evolution of the precipitating system. In order to gain understanding of microphysics complexity, behavior, and potential biases, recent research has focused on microphysics scheme performance (e.g., Cintineo et al., 2014; McMillen and Steenburgh, 2015; Morrison et al., 2015; Johnson et al., 2016) and sensitivity (e.g., Morrison and Milbrandt, 2011; Morrison et al., 2012; Van Weverberg et al., 2012). Specifically, polarimetric radar data is a powerful tool for comparing model

\footnotetext{
* Corresponding author: Yongsun JUNG

Email: youngsun.jung@ou.edu
}

output with observations (e.g., Jung et al., 2012; Dawson et al., 2013; Brown et al., 2016; Putnam et al., 2017) because radar polarimetry can provide observational microphysics information (i.e., differential reflectivity $Z_{\mathrm{DR}}$ is related to hydrometeor shape)

Microphysics schemes in NWP models typically represent particle size distributions (PSDs) using a gamma distribution:

$$
N(D)=N_{0} D^{\mu} \exp (-\Lambda D)
$$

where $N_{0}, \mu$ and $\Lambda$ are the intercept, shape and slope parameters, respectively, and $D$ is the particle diameter. For onemoment (1M) schemes in which one PSD moment (typically mixing ratio) is predicted, $\Lambda$ typically varies freely while $N_{0}$ is usually fixed (e.g., Lin et al., 1983; Rutledge and Hobbs, 1983; Tao and Simpson, 1993; Hong and Lim, 2006) or diagnosed (i.e., as a function of temperature or mixing ratio [see Hong and Lim (2006), Thompson et al. (2008), and the Thompson graupel intercept parameter in Morrison et al. 
(2015)]. Diagnosing $N_{0}$ in $1 \mathrm{M}$ schemes allows $N_{0}$ to vary, but not independently of its tied parameter (i.e., mass). Diagnostic $N_{0}$ has shown improvement over fixed $N_{0}$ (Zhang et al., 2008; Wainwright et al., 2014; Pan et al., 2016), while improvement was not as clear in other studies (Straka et al., 2005; Milbrandt and Yau, 2006; Van Weverberg et al., 2011). As previous studies have focused mainly on convective events, additional studies regarding the tuning of $N_{0}$ to large-scale events would be helpful for regional forecasts.

Two-moment (2M) schemes add an additional predicted variable (typically number concentration) that allows $N_{0}$ to vary independently of mass (e.g., Milbrandt and Yau, 2005; Morrison et al., 2009; Mansell et al., 2010). Several studies have compared $1 \mathrm{M}$ microphysics scheme performance with multi-moment (2M or higher) schemes. While $1 \mathrm{M}$ schemes are theoretically computationally faster than multi-moment schemes with additional predicted moments, one of the largest deterrents of employing 1M schemes are their inability to replicate size sorting (e.g., Dawson et al., 2010, 2014; Jung et al., 2010; Johnson et al., 2016), a fundamental microphysical process where larger hydrometeors fall faster than smaller ones. This mechanism is presumably more important in deep convective storms within directional wind shear environments, where a strong updraft allows larger hydrometeor growth (and subsequently, size difference) and transport sedimentation spatially distributes them.

It is desirable that microphysics schemes retain consistent performance over various precipitation modes. However, some microphysics schemes have been developed and tested for (and therefore, potentially biased toward) largescale (e.g., Wilson and Ballard, 1999; Hong and Lim, 2006; Thompson et al., 2008) or storm-scale precipitation systems (e.g., Milbrandt and Yau, 2005; Morrison et al., 2009; Mansell et al., 2010). As horizontal grid resolution decreases, the microphysical processes and parameterizations in the scheme do not necessarily change. Ideally, microphysics performance remains unchanged with varying grid scale. In reality, microphysics schemes have the potential to grow model error when they run outside scales for which they are tuned. For example, microphysics schemes tuned for large-scale precipitation systems might favor small rain drops through aggressive breakup and could poorly simulate large raindrops often seen in supercell storms. While some studies have examined model performance sensitivity to horizontal grid resolution (e.g., Bryan and Morrison, 2012; Potvin and Flora, 2015; Verrelle et al., 2015), more rigorous study across several microphysics schemes is needed to provide guidance for microphysics scheme improvement by modelers and help users choose the best microphysics/resolution combination for their modeling purposes.

While some of the studies previously mentioned have shown the superior performance of multi-moment microphysics schemes over $1 \mathrm{M}$ schemes, $1 \mathrm{M}$ schemes are still popular for operational models primarily because of their low computational cost. Further, some studies provide optimism that $1 \mathrm{M}$ scheme performance could be improved. The Thompson microphysics scheme, whose snow processes use
$1 \mathrm{M}$ parameterization (i.e., snow mixing ratio is predicted) with a combination of two PSDs, predicts accumulated snowfall closer to observed totals than other $1 \mathrm{M}$ schemes and performs similarly to the Morrison 2M scheme in Liu et al. (2011). Further, Bryan and Morrison (2012) demonstrated that increasing grid resolution noticeably increased $1 \mathrm{M}$ performance in terms of surface precipitation and storm evolution for a simulated squall line, although the $2 \mathrm{M}$ scheme still outperformed the $1 \mathrm{M}$ scheme.

This current study examines the performance of the Unified Model (UM) microphysics scheme using two distinct cases: a Changma front, and Typhoon Sanba (2012) over the Korean peninsula. Polarimetric variables are computed from UM output using the radar simulator based on Jung et al. $(2008,2010)$ and compared to observations from the Biseulsan radar, which is an S-band polarimetric radar. It is one of six radars operated by the Ministry of Land, Infrastructure and Transport to improve flood forecasts. More details on the radar can be found in Park et al. (2015b). This study aims to identify any biases and weaknesses present so that modelers can improve the scheme and help researchers and forecasters to interpret forecasts given microphysical biases. The paper is organized as follows: section 2 details the UM configuration and the polarimetric radar data simulator; section 3 compares the structure of polarimetric observations with UM simulated polarimetric variables; section 4 analyzes the polarimetric distributions; section 5 expands the comparisons to frozen hydrometeors; and section 6 provides conclusions.

\section{Overview of UM microphysics and the po- larimetric radar data simulator}

\subsection{UM microphysics}

The UM microphysics scheme is rooted in Wilson and Ballard (1999) [itself derived from Rutledge and Hobbs (1983)], although modifications continue to update and improve the scheme (e.g., Wilkinson et al., 2013). The UM microphysics scheme is unique in that it contains many parameterization choices. Here, we list relevant parameterizations in Korea Meteorological Administration (KMA) model simulations. At the most basic level, UM microphysics contains three hydrometeor categories: cloud water, rain, and ice. The default UM microphysics scheme is unique in that cloud ice and snow are contained in the ice category, although an option exists to separate these into individual categories. In our simulations, the ice category is represented by a single generic ice distribution (Field et al., 2005, 2007). Further, the UM microphysics configuration employed in this study contains an additional graupel category, an essential hydrometeor category for deep convection. Briefly, the UM is centered at $37.57^{\circ} \mathrm{N}, 126.97^{\circ} \mathrm{E}$ over the Korean peninsula on $744 \times 928$ grid points with a predominant horizontal grid spacing $\Delta x$ of $1.5 \mathrm{~km}$, and includes 21 grid points of varying grid zones with $\Delta x$ increasing to $4 \mathrm{~km}$ at the lateral boundaries. The model contains 70 terrain-following vertical levels up to 39 $\mathrm{km}$. The model is integrated using a semi-implicit, semi- 
Lagrangian method, with time step $\Delta t=50 \mathrm{~s}$ and model output every hour. Forecasts are initialized at 0000 UTC using three-dimensional variational data assimilation every $6 \mathrm{~h}$ and integrated up to $36 \mathrm{~h}$. More details can be found in Table 1 .

In our configuration, the PSDs are exponential for rain, gamma for graupel, and a linear combination of exponential and gamma distributions for ice (Table 2). As the hydrometeor categories use $1 \mathrm{M}$ parameterization, $N_{0}$ must be parameterized in the PSDs. Rain and graupel $N_{0}$ is a power-law function of the slope parameter $\Lambda$ :

$$
N_{0}=n_{\mathrm{ax}} \Lambda^{n_{\mathrm{bx}}},
$$

where $n_{\mathrm{a} x}$ and $n_{\mathrm{b} x}$ are constants for hydrometeor $x$. The rain $N_{0}$ relationship is from Abel and Boutle (2012). Ice $N_{0}$ is a function of the second and third moments of the ice distribution $M_{2}$ and $M_{3}$ (Field et al., 2007). Rain and graupel densities are set to 1000 and $500 \mathrm{~kg} \mathrm{~m}^{-3}$, respectively. Ice assumes a power-law mass relationship that does not assume a spherical shape, resulting in varying bulk density.

Table 1. UM configuration.

\begin{tabular}{|c|c|c|}
\hline UM configuration & & Description \\
\hline \multirow[t]{2}{*}{ Grid } & Horizontal & Arakawa C-grid \\
\hline & Vertical & Charney-Phillips grid staggering \\
\hline Map projection & & $\begin{array}{l}\text { Rotated latitude and longitude } \\
\text { coordinate system }\end{array}$ \\
\hline Time integration & & Semi-implicit, semi-Lagrangian \\
\hline Model version & & Vn 8.2 \\
\hline \multirow[t]{2}{*}{ Domain } & Horizontal & $\begin{array}{c}\text { Varying grid spacing: } 4 \mathrm{~km} \rightarrow \\
1.5 \mathrm{~km} ; 744 \times 928 \text { grid points }\end{array}$ \\
\hline & Vertical & $\begin{array}{l}70 \text { levels (up to } 39 \mathrm{~km} \text { ); terrain- } \\
\text { following } \eta \text { system }\end{array}$ \\
\hline$\Delta t$ & & $50 \mathrm{~s}$ (short-time step: $30 \mathrm{~s}$ ) \\
\hline Radiation & & $\begin{array}{l}\text { Spectral band radiation (general } \\
\text { 2-stream and radiance) }\end{array}$ \\
\hline Surface physics & & JULES land-surface scheme \\
\hline PBL scheme & & $\begin{array}{l}\text { Non-local scheme with revised } \\
\text { diagnosis of K profile depth }\end{array}$ \\
\hline $\begin{array}{l}\text { Cumulus parameter- } \\
\text { ization }\end{array}$ & & None \\
\hline Microphysics & & $\begin{array}{l}\text { Single-moment UM microphysics } \\
\text { with graupel }\end{array}$ \\
\hline
\end{tabular}

Table 2. Summary of the hydrometeor PSDs in the UM microphysics examined in this study.

\begin{tabular}{llccc}
\hline Hydrometeor & Distribution $N(D)$ & $n_{\mathrm{ax}}$ & $n_{\mathrm{bx}}$ & $\mu$ \\
\hline Rain & $N_{0} D^{\mu} \exp (-\Lambda D)$ & 0.22 & 2.2 & 0.0 \\
Graupel & $N_{0} D^{\mu} \exp (-\Lambda D)$ & $5 \times 10^{25}$ & -4.0 & 2.5 \\
\cline { 2 - 4 } Ice & $\frac{M_{2}^{4}}{M_{3}^{3}}\left[141 \exp \left(-16.8 \frac{M_{2}}{M_{3}} D\right)\right.$ \\
& \multicolumn{1}{c}{$\left.+102\left(\frac{M_{2}}{M_{3}} D\right)^{2.07} \exp \left(-4.82 \frac{M_{2}}{M_{3}} D\right)\right]$} \\
\end{tabular}

Note: $M_{2}$ and $M_{3}$ are the second and third moments of the ice distribution, respectively. $D$ is the particle diameter.

\subsection{Polarimetric radar simulator}

The polarimetric radar simulator employed in this study to compute polarimetric variables is well-documented in the literature (Jung et al., 2008, 2010; Dawson et al., 2014). Briefly, the simulator constructs PSDs from model output consistent with UM microphysical assumptions. However, we acknowledge that the generic ice category is treated as snow (and will be referred to as snow for the remainder of the paper) with a constant density of $100 \mathrm{~kg} \mathrm{~m}^{-3}$ for scattering purposes. This should not be a large source of error, as high-density ice crystals are quite small in the PSD used in the scheme, and thus contribute little to polarimetric calculations. The water fraction is diagnosed using a linear relationship as a function of temperature. As temperature increases from $-2.5^{\circ} \mathrm{C}$ to $2.5^{\circ} \mathrm{C}$ for snow and from $-5^{\circ} \mathrm{C}$ to $0^{\circ} \mathrm{C}$ for graupel, the water fraction increases from 0 to 0.8 for snow and from 0 to 0.4 for graupel. These temperature and water fraction ranges are chosen to tune the simulated melting layer to match observations in terms of depth and intensity. Finally, scattering amplitudes are retrieved from precomputed $T$-matrix tables that vary with particle diameter and water fraction. Polarimetric variables reflectivity at horizontal polarization $\left(Z_{\mathrm{H}}\right)$, differential reflectivity $\left(Z_{\mathrm{DR}}\right)$, specific differential phase $\left(K_{\mathrm{DP}}\right)$, and the correlation coefficient $\left(\rho_{\mathrm{HV}}\right)$, are computed from these scattering amplitudes (Zhang et al., 2001; Jung et al., 2010). For more details on the polarimetric simulator, please refer to the above mentioned publications.

\section{Polarimetric structure for the model and observations}

In this section, the polarimetric simulator is applied to two distinct weather cases - a Changma front, and Typhoon Sanba (2012) — and compared to observed polarimetric variables measured by the Biseul-san radar. For forecast verification, it is typical to compare observations and model forecasts valid at the same time. However, position error that grows fast during the forward model integration makes it difficult to compare precipitation systems in the same domain, especially when the verification data have limited coverage (i.e., the Biseul-san radar utilized in this study only covers $150 \mathrm{~km})$. As radar beam height increases with increasing distance, precipitation systems that are being compared should be at a similar distance from the radar. In addition, polarimetric measurements exhibit large dynamic ranges depending on widely varying PSDs within the precipitation system. It would be more practical to compare the variables in the radar echoes that show similar characteristics in both observations and model simulations. Therefore, we compare precipitation systems showing similar qualitative reflectivity structure (i.e., rainbands) and distance from the radar in the observed and model reflectivity to allow for temporal errors.

Because the prevailing geography of Korea is mountainous, many radars are placed on the tops of mountains and the lowest elevation angles are below $0^{\circ}$ (e.g., $-0.5^{\circ}$ ). The 
Biseul-san radar used in this study is located on the top of Biseul Mountain (1085 m above mean sea level). We analyze model and observational plots of polarimetric and microphysical variables at the $0.5^{\circ}$ elevation angle to ensure the primary precipitating hydrometeor is rain, eliminating substantial ground clutter contamination or beam blockage. The beam height of this elevation angle (taking into account radar altitude and Earth's curvature) within the radar coverage is below $4000 \mathrm{~m}$.

\subsection{Changma front (10 July 2012)}

At 0000 UTC 10 July 2012, an east-west Changma front attached to a low-pressure system was positioned west of the Korean peninsula (not shown). While the low gradually detached from the Changma front and moved northeast, the Changma front settled just over the southern part of the Korean peninsula near the coastline at 0000 UTC 11 July 2012 (Fig. 1a). The green line shows the $20^{\circ} \mathrm{C}$ isodrosotherm, and the Changma front is often located south of this line. Figure $1 \mathrm{~b}$ depicts the accumulated rainfall from AWS rain gauges on the peninsula over $12 \mathrm{~h}$, interpolated linearly over the domain. Accumulated rainfall exceeds $100 \mathrm{~mm}$ sparingly in the middle of the Korean southern coast, which is where the Changma front is positioned. Further north, accumulated rainfall continually decreases and even falls below $5 \mathrm{~mm}$, notably in the central and eastern parts of South Korea. These regions possibly received little rainfall because the stationary front stayed to the south and the low-pressure system moved to the northeast.

Figure 2 shows the radar observations of the Changma front at 2130 UTC 10 July 2012, and model output for the simulated Changma front, analyzed at the 3 -h forecast valid at 2100 UTC. $Z_{\mathrm{DR}}$ and $K_{\mathrm{DP}}$ contain $0.3 \mathrm{~dB}$ and $0.02^{\circ} \mathrm{km}^{-1}$ thresholds, respectively, to suppress noise. Overall, $Z_{\mathrm{H}}$ shows widespread precipitation up to $55 \mathrm{dBZ}$, with rather smooth gradients (Fig. 2a). $Z_{\mathrm{DR}}$ (Fig. 2c) is generally below $2 \mathrm{~dB}$, indicating the main precipitating hydrometeors are likely small to medium-sized. $K_{\mathrm{DP}}$ (Fig. $2 \mathrm{e}$ ) is noisy over the radar coverage domain, except for high reflectivity cores in the south. Small areas of $K_{\mathrm{DP}}$ exceed $1^{\circ} \mathrm{km}^{-1}$ in the main precipitation cores $\left(Z_{\mathrm{H}}>35 \mathrm{dBZ}\right)$, indicating heavy precipitation. Observed $\rho_{\mathrm{HV}}$ is very high (Fig. $2 \mathrm{~g}$ ) over the entirety of the precipitation area, except for sparse reduced values in low signal-to-noise ratio regions. The overall large $\rho_{\mathrm{HV}}$ values

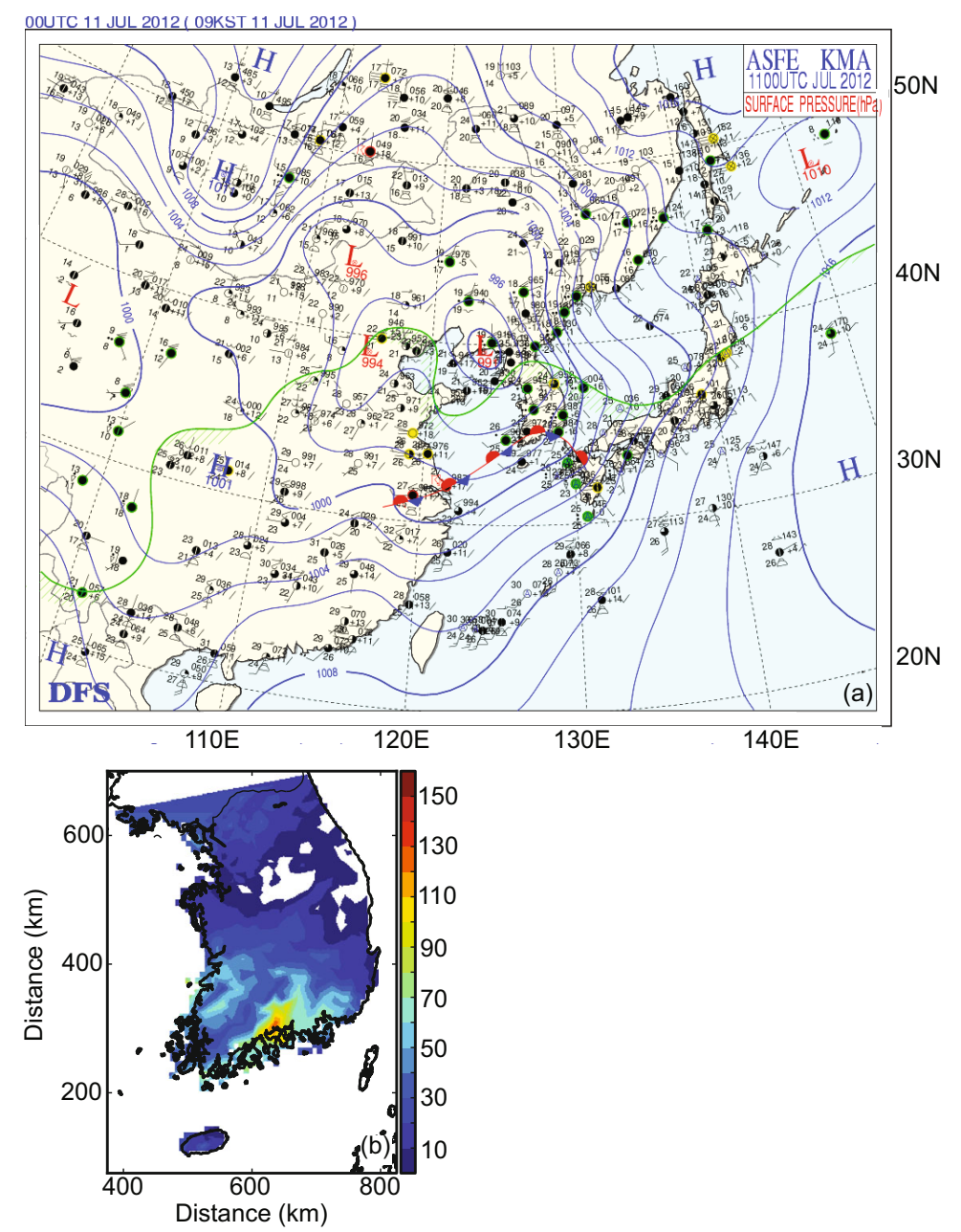

Fig. 1. The (a) surface chart at 0000 UTC 11 July 2012 and (b) rain accumulation (units: $\mathrm{mm}$ ) from AWS gauge data over $12 \mathrm{~h}$ ending at 2330 UTC 10 July 2012 for the Changma front case. 

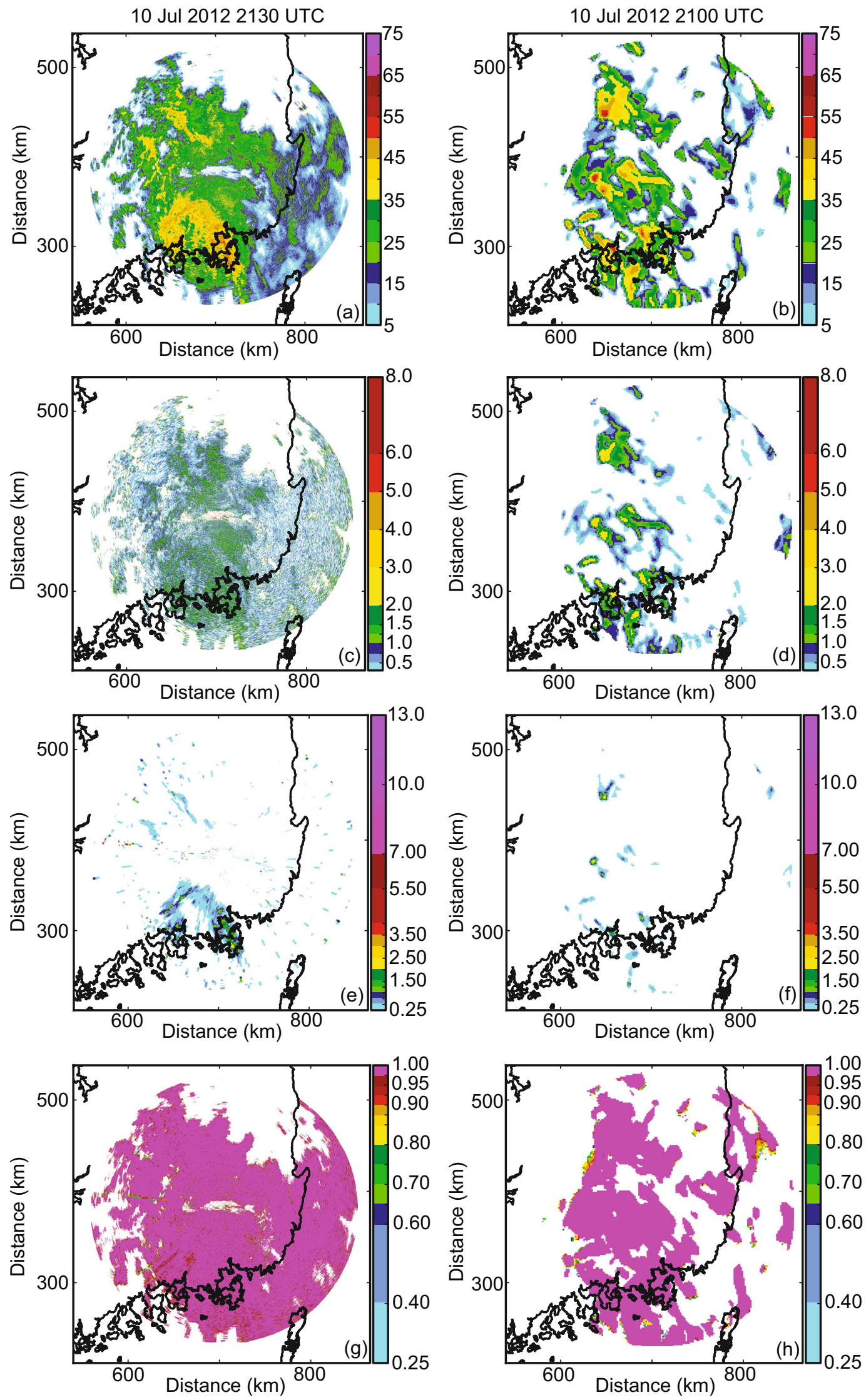

Fig. 2. The (a, b) $Z_{\mathrm{H}}$ (units: dBZ), (c, d) $Z_{\mathrm{DR}}$ (units: dB), (e, f) $K_{\mathrm{DP}}$ (units: ${ }^{\circ} \mathrm{km}^{-1}$ ) and $(\mathrm{g}, \mathrm{h}) \rho_{\mathrm{HV}}$ at 2130 UTC 10 July 2012 in observations (left-hand panels) and the model (right-hand panels) for the Changma front valid as a 3 -h forecast at 2100 UTC 10 July 2012 at the $0.5^{\circ}$ elevation angle. 
indicate the precipitating system at low levels is dominated by the presence of pure rain.

The storm structure of the simulated Changma front (Fig. $2 b$ ) is more detached compared to observations. Isolated high $Z_{\mathrm{H}}$ cores with narrow stratiform rain are scattered within the radar coverage. Model underprediction of precipitation coverage is evident, as observed precipitation coverage (defined as $Z_{\mathrm{H}} \geqslant 5 \mathrm{dBZ}$ ) is $75 \%$ of the radar coverage area, compared to the model's $42 \%$ (Fig. 2b). From the microphysics perspective, the diagnostic intercept parameter is likely one of the main reasons for the fragmented storm organization. As rain mass decreases toward the storm edges, drop size decreases rapidly and inversely proportional to the mixing ratio, and becomes increasingly prone to evaporation which is proportional to the rain intercept parameter. Subsequent timesteps with reduced rain mass result in an increased diagnosed rain $N_{0}$, which further increases evaporation and decreases drop size. Further, other studies using the UM with grid spacing smaller than a few $\mathrm{km}$ have identified the model's struggle to adequately resolve convection, both in size and intensity (e.g., Tang et al., 2013). There are other studies that have tried to attribute overly intense cores and a lack of precipitation coverage to the local non-conservation associated with semi-Lagrangian advection and/or deficits in the subgrid turbulence scheme (e.g., Hanley et al., 2015; Nicol et al., 2015). While those studies revealed sensitivity, the main issue of overly intense updrafts and too little light rain remained.

The model also produces higher $Z_{\mathrm{DR}}$ values $(>2 \mathrm{~dB}$; Fig. 2d) in the precipitation cores compared to observations. Given the $1 \mathrm{M}$ nature of UM microphysics, $D_{0 \mathrm{r}}$ is monotonically related to rain mass. Thus, increasing reflectivity (increasing rain rate) corresponds to increasing median drop size, resulting in larger $Z_{\mathrm{DR}}$ in the reflectivity cores. Outside of the cores, $Z_{\mathrm{DR}}$ is frequently below $1 \mathrm{~dB}$, which is somewhat similar to observations. Similar to observed $K_{\mathrm{DP}}$, significant $K_{\mathrm{DP}}$ values (Fig. $2 \mathrm{f}$ ) are found only in the precipitation cores with large drops. Although the spatial coverage of simulated $K_{\mathrm{DP}}$ is significantly underpredicted similar to $Z_{\mathrm{H}}$ and $Z_{\mathrm{DR}}$, the range of simulated $K_{\mathrm{DP}}\left(0.25-3^{\circ} \mathrm{km}^{-1}\right)$ is very similar to that of observations. The model $\rho_{\mathrm{HV}}$ (Fig. $2 \mathrm{~h}$ ) is generally near 1 over the analyzed domain, indicating the primary precipitating hydrometeor at low levels is rain, matching observations. The sparse model $\rho_{\mathrm{HV}}$ reduction is caused by interpolation error of model polarimetric variables to the radar elevation angle.

\subsection{Typhoon Sanba (17 September 2012)}

Typhoon Sanba (2012) made landfall on the southern coastline of the Korean peninsula. Surface charts at 0000 UTC 17 September 2012 reveal an intense low of $955 \mathrm{hPa}$ with maximum winds reaching $148 \mathrm{~km} \mathrm{~h}^{-1}$ as the typhoon's center was positioned just south of the Korean coastline (Fig. 3a). The UM forecast is able to simulate the large-scale structure of Typhoon Sanba (2012) reasonably well, capturing the location of the heavy precipitation in the eyewall and rainbands (Fig. 3b). The highest 12-h accumulated rainfall over the peninsula is concentrated over the south (Fig. 3c), where the eyewall made landfall. The maximum substantially exceeds that in the Changma front case. A few stations reported over $400 \mathrm{~mm}$ of rain accumulation, with one exceeding 500 $\mathrm{mm}$. The typhoon weakened as it made landfall but heavy rain continued to cause substantial damage while the typhoon moved northeast.

The observations considered for this case are at 0100 UTC 17 September 2012. The eye of the typhoon is just south of the coastline, with the typhoon's rainbands in the north covering much of the radar coverage area (Fig. 4a). $Z_{\mathrm{H}}$ reveals widespread moderate to heavy precipitation. Further from the eyewall, precipitation becomes lighter at the edge of the radar coverage. It appears drops are relatively larger close to the typhoon's eye, where high $Z_{\mathrm{DR}}$ is found (Fig. $4 c)$. Given the convective nature of the rainbands, drops have more potential to grow before falling out of the updrafts. Significant observed $K_{\mathrm{DP}}$ is found in the inner part of the eyewall, with maximum $K_{\mathrm{DP}}$ exceeding $2^{\circ} \mathrm{km}^{-1}$ (Fig. 4e). The $\rho_{\mathrm{HV}}$ is generally near 1 over the entire radar coverage area, which makes sense given the warm-rain processes that dominate typhoons (Fig. 4g).

The isolated convective cores seem less problematic for the UM simulated typhoon compared to the previous case, suggesting that the performance of the microphysics scheme may depend on the scale of the precipitation system (Fig. 4b). In fact, the microphysics scheme was originally developed for large-scale systems. The simulated high reflectivity near the coastline is consistent with observations that show the northern part of the eyewall/rainbands. Still, precipitation coverage is underpredicted, as the model precipitation encompasses $76 \%$ of the radar coverage area compared to the observational $90 \%$, possibly due to the $N_{0}$ relationship and semi-Lagrangian/subgrid turbulence dynamic reasons previously mentioned. While larger observed $Z_{\mathrm{DR}}$ appears in the inner side of the eyewall, where drops can grow large in strong convection, large model $Z_{\mathrm{DR}}$ coincides with high reflectivity throughout the domain (Fig. 4d). Enhanced model $K_{\mathrm{DP}}$ is also found further away from the eye, collocating with high reflectivity and $Z_{\mathrm{DR}}$ (larger drops; Fig. 4f) because of their monotonic relationships with $q_{\mathrm{r}}$. The larger $K_{\mathrm{DP}}$ found near the edges of the radar domain is due to snow. The model $\rho_{\mathrm{HV}}$ is generally near 1 , and only a minor reduction is found in sparse areas near the edges of the domain due to snow and graupel, and interpolation error (Fig. 4h). Thus, the primary model hydrometeor is pure rain, which matches observations and the expected hydrometeor behavior of a typhoon given its dominant warm-rain processes.

\section{Polarimetric distributions}

\subsection{Changma front}

In order to evaluate the ability of UM microphysics to capture the natural variation of PSDs, observed, model, and model rank histograms of polarimetric variables are constructed for the two test cases (Figs. 5 and 6). All of the histograms use orange, green, blue, purple and violet shaded 

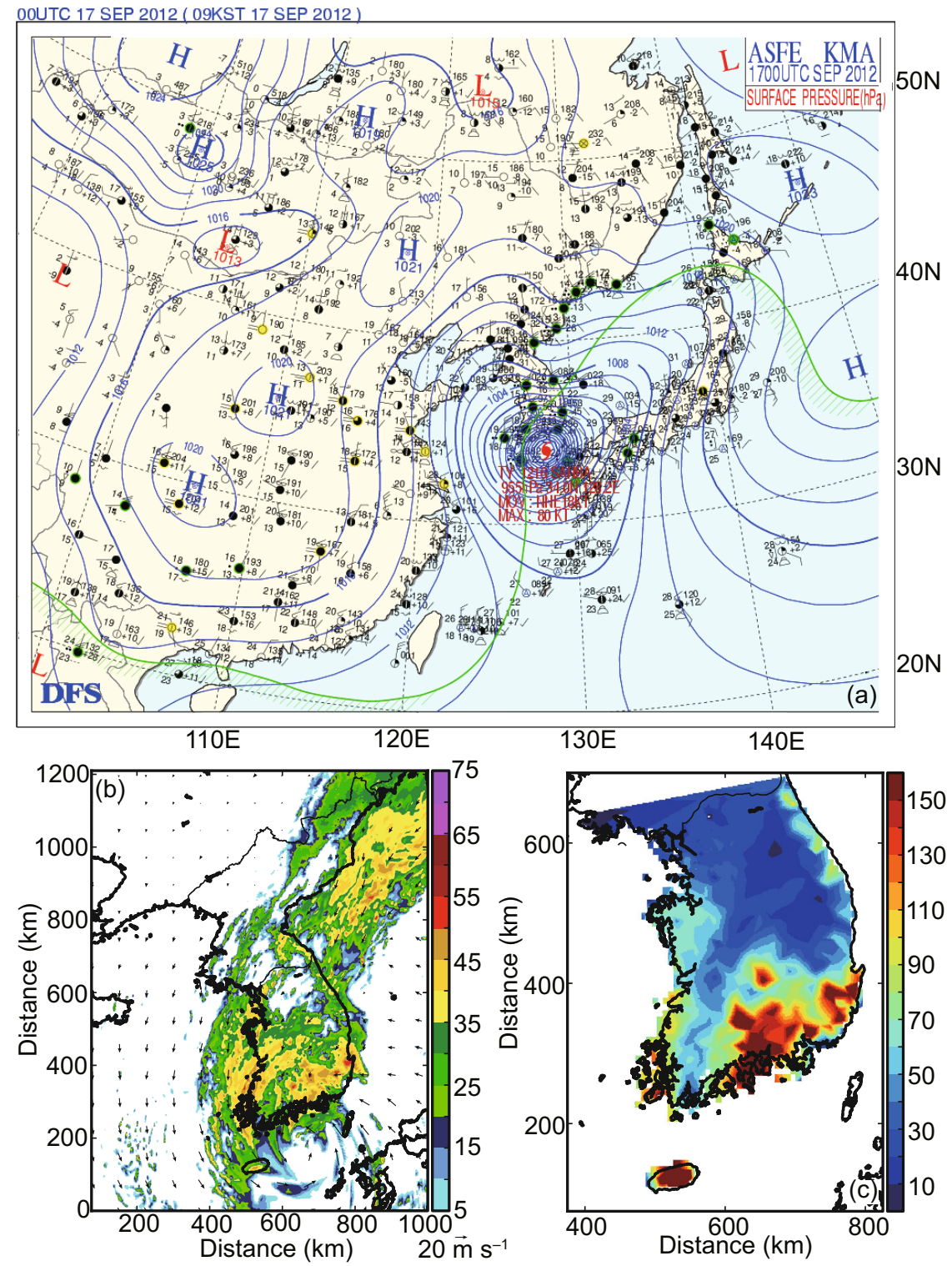

Fig. 3. The (a) surface chart at 0000 UTC 17 September 2012, (b) simulated reflectivity $Z_{\mathrm{H}}$ for the UM 6-h forecast valid at 0000 UTC 17 September 2012 and $z=\sim 166 \mathrm{~m}$, and (c) rain accumulation (units: $\mathrm{mm}$ ) from AWS gauge data over $12 \mathrm{~h}$ ending at 0300 UTC 17 September 2012 for Typhoon Sanba (2012).

areas to denote the 0.2 percentiles in the distribution. The observation and model rank plots denote the observation 0.2 percentiles (to facilitate comparison between the model and observations), while the model histograms denote the model 0.2 percentiles. The observations and UM contain different resolutions and thus a different number of data points; therefore, a raw comparison is not valid. The model rank histograms are constructed by sorting observed data, finding locations of percentiles spaced at 0.1 , and then distributing the model data into these observed percentiles. By analyzing how the model data fills the observed percentiles, a direct comparison between the model and observed distributions is possible, and model biases are readily apparent. The black solid lines in the plots represent model uniform distributions (hereafter UDs), which would occur if the model data perfectly matched the observed distribution. The 5-dBZ threshold in all plots, and additional $0.3-\mathrm{dB}$ and $0.25^{\circ} \mathrm{km}^{-1}$ thresholds, are included in the histograms to filter noisy data. Additionally, observations are removed when the $\rho_{\mathrm{HV}}$ is less than 0.9 , because precipitation is mostly pure rain at the $0.5^{\circ}$ elevation angle. It is important to mention that comparisons among cases should be taken with caution because of the small coverage of the radar used in this study. It only captures part of the precipitation, and therefore the results may not be representative of the entire storm system.

Observation and model reflectivity histograms are binned at $1 \mathrm{dBZ}$ (Figs. 5a and b). The model Changma front reflectivity distribution tends to contain a larger frequency of smaller reflectivity values $(<15 \mathrm{dBZ})$ than observations, while missing the larger peak of observed reflectivity $(\sim 30 \mathrm{dBZ})$. This 

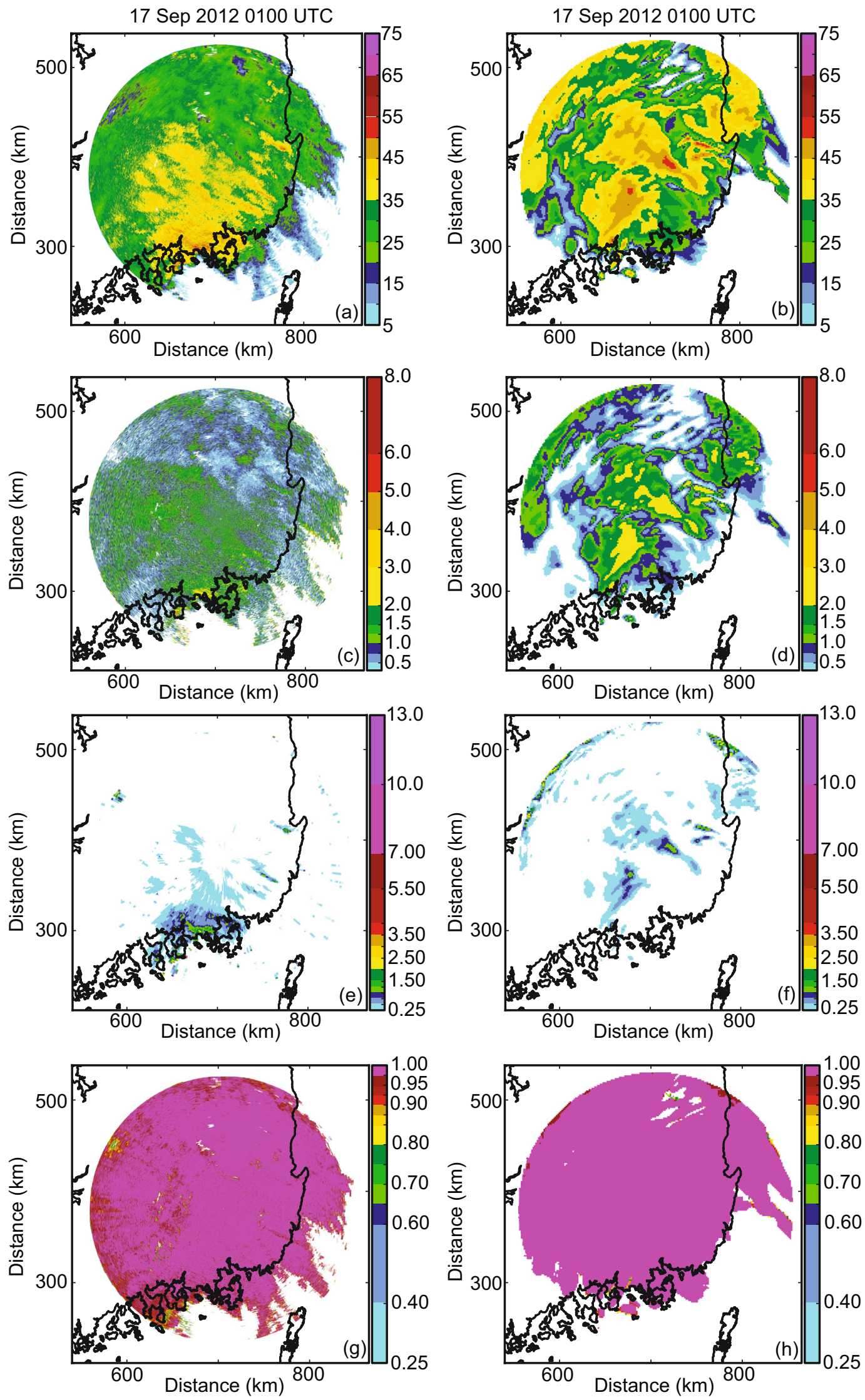

Fig. 4. The (a, b) $Z_{\mathrm{H}}$ (units: dBZ), (c, d) $Z_{\mathrm{DR}}$ (units: dB), (e, f) $K_{\mathrm{DP}}$ (units: ${ }^{\circ} \mathrm{km}^{-1}$ ) and $(\mathrm{g}, \mathrm{h}) \rho_{\mathrm{HV}}$ at 0100 UTC 17 September 2012 in observations (left-hand panels) and the model (right-hand panels) for Typhoon Sanba (2012) valid as a 7-h forecast at 0100 UTC 17 September 2012 at the $0.5^{\circ}$ elevation angle. 

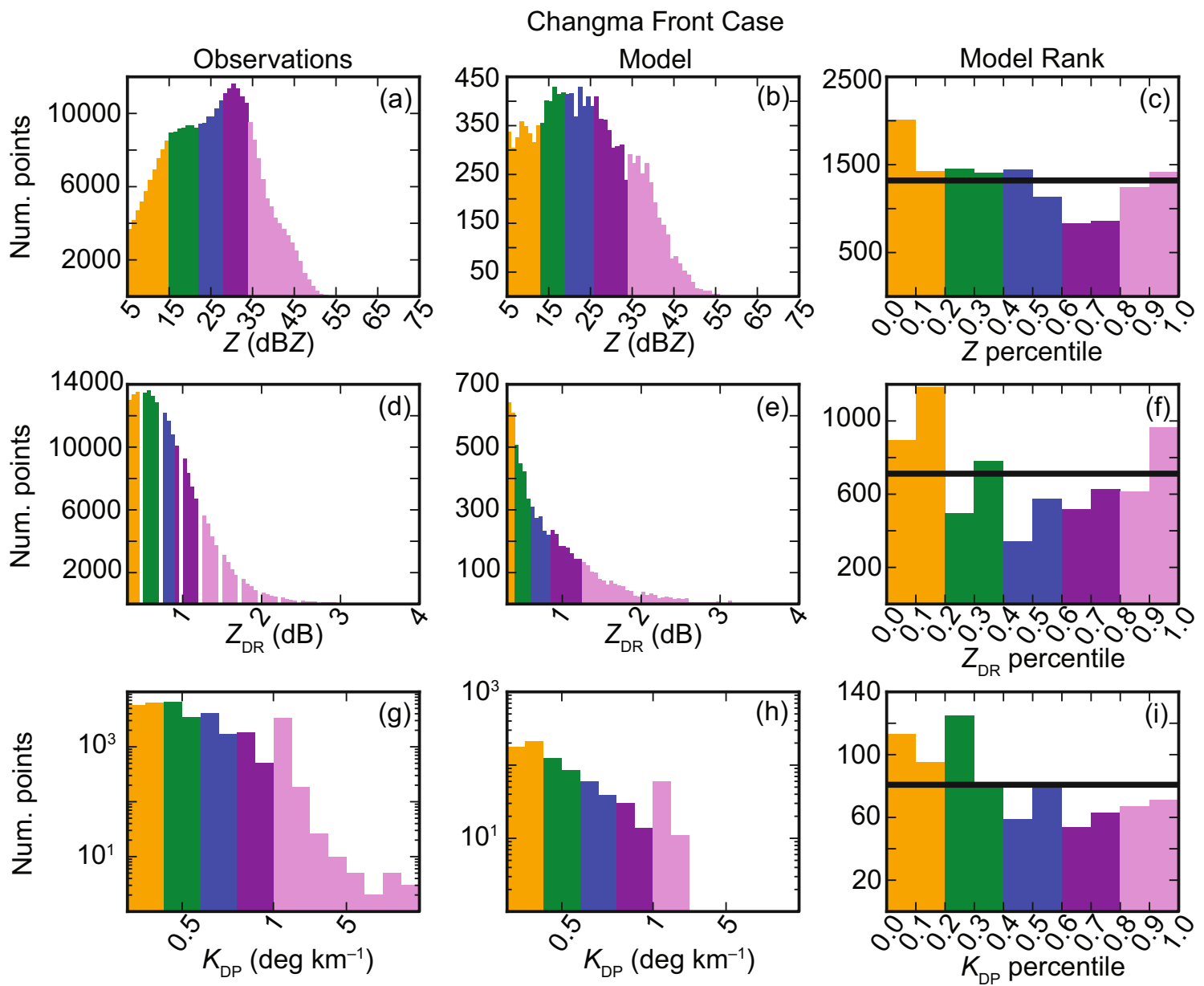

Fig. 5. Observed (left-hand panels), model (middle panels), and model rank (right-hand panels) of (a-c) $Z$ (units: dBZ), (d-f) $Z_{\mathrm{DR}}$ (units: $\mathrm{dB}$ ) and $(\mathrm{g}-\mathrm{i}) K_{\mathrm{DP}}$ (units: ${ }^{\circ} \mathrm{km}^{-1}$ ) for the Changma front case. Percentiles at 0.2 intervals are denoted by color shifts in the plots. The observation and model rank plots display observation percentiles, while the model plots show model percentiles. The black lines in the model rank column denote a theoretical UD in which model data are distributed in the same manner as observations.

is also reflected in the model rank histogram, as the $0.0-0.5$ percentile bins exceed the model UD and dip below this line between the $0.5-0.9$ percentiles where the observation reflectivity peak is centered (Fig. 5c). The model rank histogram slightly rises above the UD line in the largest percentile bin, but there is a clear underprediction of overall reflectivity.

Observational $Z_{\mathrm{DR}}$ produces a smooth distribution at $0.05-\mathrm{dB}$ bin intervals, albeit with several missing bins (Fig. $5 \mathrm{~d})$. This is due to observational $Z_{\mathrm{DR}}$ rounding, where observations are stored at $0.06-0.07-\mathrm{dB}$ intervals. As a result, the missing bins repeat for bins ending at $0.25 \mathrm{~dB}$ intervals. One notable difference between the two histograms is that the model $Z_{\mathrm{DR}}$ frequency continually decreases with increasing $Z_{\mathrm{DR}}$ (Fig. 5e), while observed $Z_{\mathrm{DR}}$ peaks in the $0.2-0.4$ percentile area. Similar to reflectivity, the model is producing more small $Z_{\mathrm{DR}}$ values compared to observations. This is reflected in the model rank $Z_{\mathrm{DR}}$ histogram, where the $0.0-0.2$ percentiles exceed the UD (Fig. 5f). The repeating low-high step shape of the histogram is thought to be due to the observational $Z_{\mathrm{DR}}$ rounding previously mentioned. The model rank histogram also reveals a longer model $Z_{\mathrm{DR}}$ tail, as the $0.9-1.0$ percentile exceeds the UD. Much of the middle $Z_{\mathrm{DR}}$ percentiles (0.2-0.8) are below the UD line, lending to the relatively higher number of low/high model $Z_{\mathrm{DR}}$ frequency. The observation and model $K_{\mathrm{DP}}$ histograms are similar in that small $K_{\mathrm{DP}}$ dominates the frequency (Figs. $5 \mathrm{~g}$ and h). For this reason, the histograms are displayed logarithmically. Compared to the model, observations contain a much longer $K_{\mathrm{DP}}$ tail. This is reflected in the model rank histogram, where the 0.6-1.0 percentiles are below the UD (Fig. 5i). On the other hand, the 0.0-0.4 percentiles are at, or exceed, the UD. Combined with the $Z$ and $Z_{\mathrm{DR}}$ histograms, large model drop size is primarily responsible for high $Z$ and $Z_{\mathrm{DR}}$ percentiles, while the rainfall amount may be underestimated.

\subsection{Typhoon Sanba (2012)}

For Typhoon Sanba (2012), both the observation and model reflectivity distributions seem to be negatively skewed Gaussian (Figs. 6a and b), and have narrower distributions compared to the Changma case. However, the model $Z$ contains higher frequencies of smaller and larger reflectivity compared to observations (Fig. 6c). A U-shaped model rank histogram is prominent in this case, in which the smallest and largest percentiles exceed the UD, while middle per- 

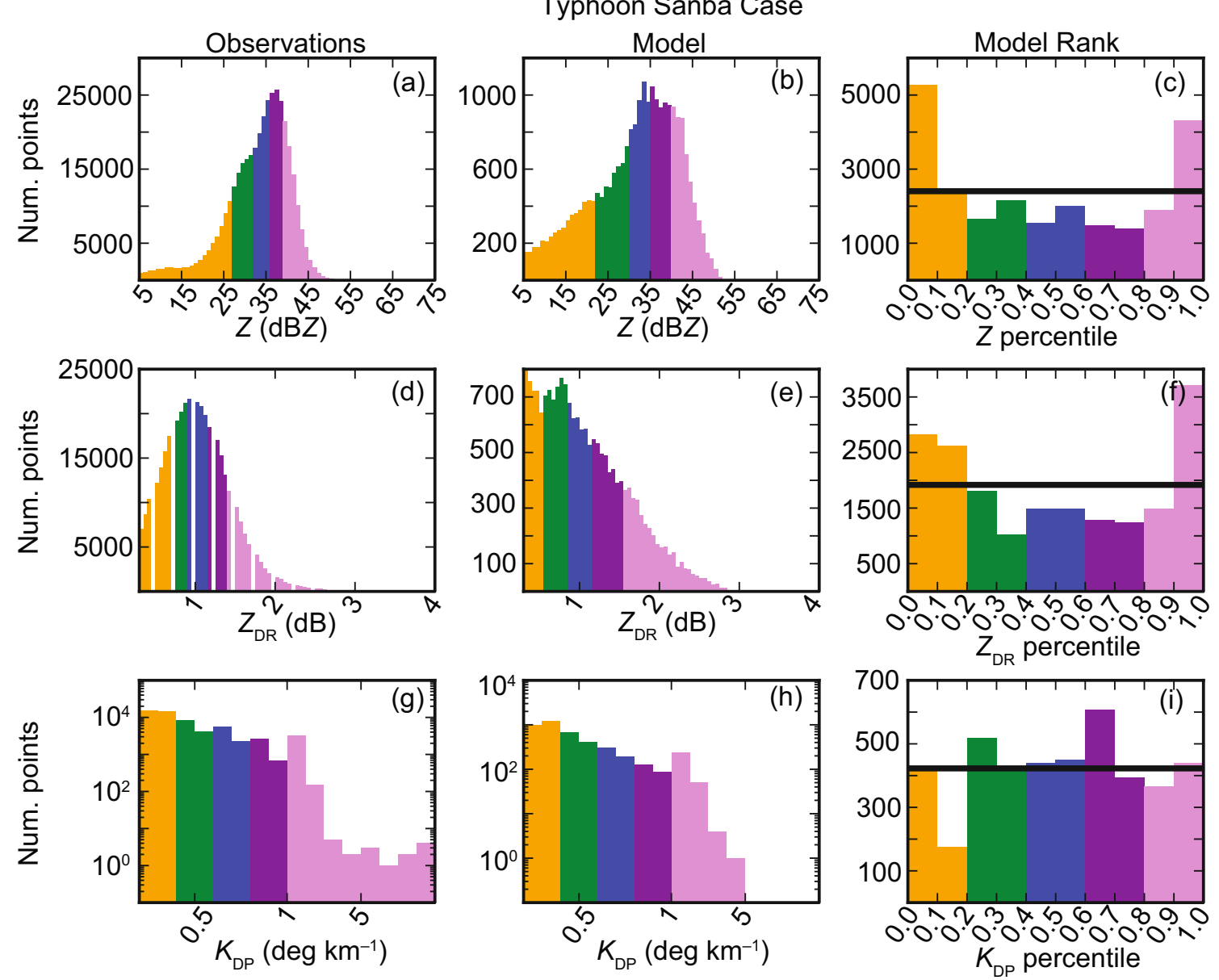

Fig. 6. As in Fig. 5 but for the typhoon case.

centiles stay under the line. Unlike reflectivity, the shapes of the $Z_{\mathrm{DR}}$ distributions are quite different. Observational $Z_{\mathrm{DR}}$ produces a smooth normal distribution with a peak at around $1 \mathrm{~dB}$, which is larger than the above case. Conversely, the model $Z_{\mathrm{DR}}$ does not have a Gaussian distribution and peaks at smaller values (Figs. 6d and e). A U-shaped model rank histogram suggests that the model overpredicts the frequency of both the smallest and largest raindrops (Fig. 6f). The model $Z_{\mathrm{DR}}$ also clearly has a longer tail than observations. Similar to the Changma case, the largest $Z$ and $Z_{\mathrm{DR}}$ values are rather small $\left(Z<55 \mathrm{dBZ}\right.$ and $\left.Z_{\mathrm{DR}}<3 \mathrm{~dB}\right)$ (Figs. $6 \mathrm{~b}$ and e). In this $Z_{\mathrm{DR}}$ range, the size effect on $K_{\mathrm{DP}}$ is not dominant, and thus the model $K_{\mathrm{DP}}$ shows a shorter tail compared to observations (Figs. $6 \mathrm{~g}$ and $\mathrm{h}$ ). As a result, the model rank histogram shows a rather flat distribution (Fig. 6i).

\section{Hydrometeor properties}

\subsection{Simulated vertical hydrometeor profiles}

In this section, we expand the scope of the analysis to include upper levels, the aim being to examine the sensitivity of simulated frozen hydrometeors to precipitation systems. Vertical profiles of horizontally averaged hydrometeor water content (HWC) over grid points where HWC is greater than $0 \mathrm{~g} \mathrm{~m}^{-3}$ are plotted for each case in Fig. 7. UM's generic ice category, which contains both ice crystals and snow, is generally favored over graupel at each height for the Changma front case (Fig. 7a). Graupel water content extends up to about $12 \mathrm{~km}$. The UM's propensity for ice/snow over graupel is reasonable, as Changma fronts are less convective than systems that favor rimed ice, such as supercells or squall lines. The melting level seems to be near $z=\sim 5 \mathrm{~km}$, as ice water content quickly decreases near this level and rain water content increases. The model graupel did not reach the surface, suggesting complete melting before reaching the surface.

Ice/snow is similarly favored over graupel at each height for Typhoon Sanba (2012) (Fig. 7b), but by far more than the Changma case. The ice/snow peak is more than twice that of the Changma front, exceeding $0.5 \mathrm{~g} \mathrm{~m}^{-3}$. Graupel is found within a limited layer around the freezing level, where it can grow through riming. However, heavy graupel falls out quickly, while most ice produced above the freezing level comprises small ice particles and aggregates in the typhoon (Houze, 2010). The typhoon melting level also appears to be near $z=\sim 5 \mathrm{~km}$, as frozen water content decreases and rain water increases below this height.

\subsection{Hydrometeor classifications}

Hydrometeor classification algorithms (HCAs, Park et al., 2009) are applied to the Changma front and Typhoon 

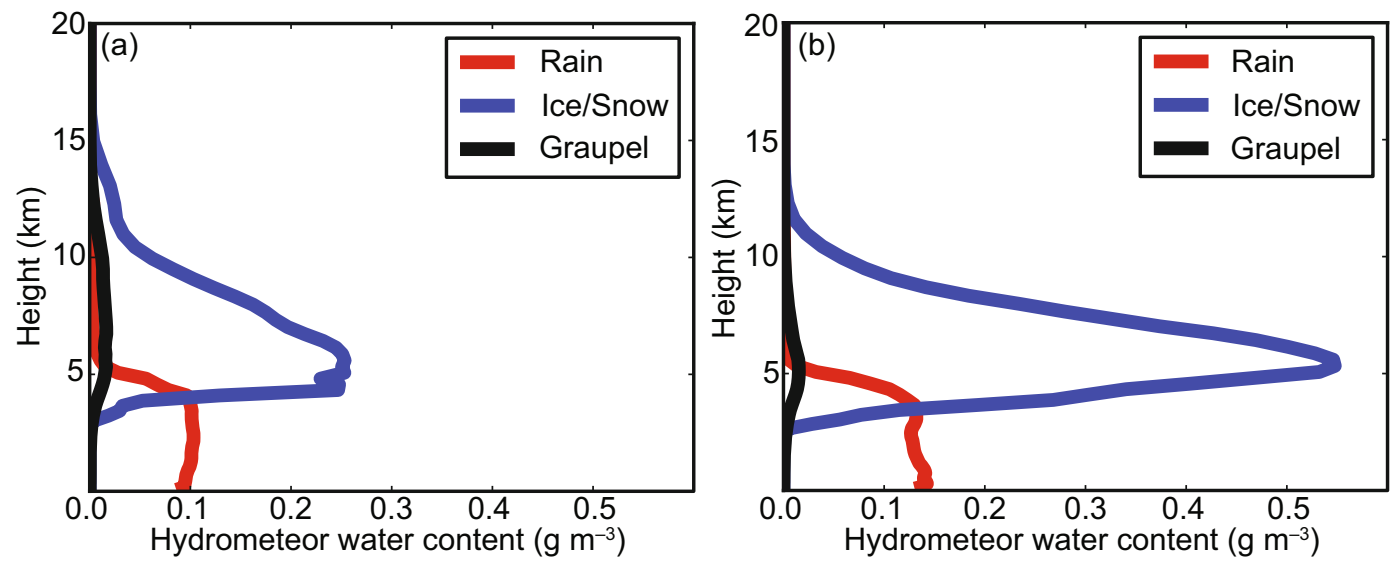

Fig. 7. Vertical plots of model rain, ice/snow and graupel horizontally averaged HWC (units: $\mathrm{g} \mathrm{m}^{-3}$ ) for the (a) Changma front and (b) Typhoon Sanba cases.
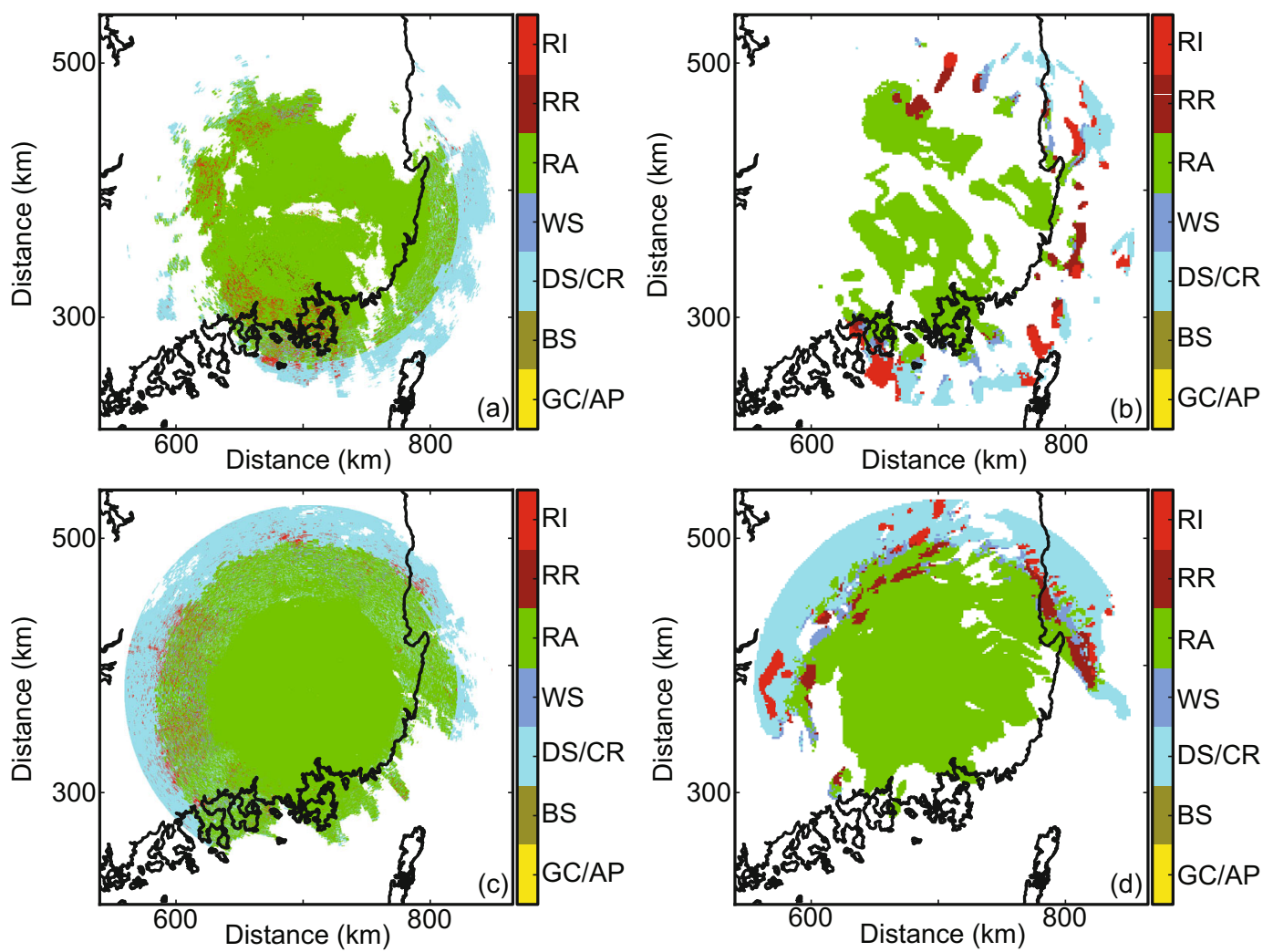

Fig. 8. HCAs for the (a, c) observations and (b, d) model in the (a, b) Changma front case and (c, d) typhoon case at the $1.6^{\circ}$ elevation angle. The hydrometeors considered are: ground clutter/anomalous propagation (GC/AP), biological scatterers (BS), dry snow/ice crystals (DS/CR), wet snow (WS), rain (RA), rain/rimed ice (RR), and rimed ice (RI).

Sanba (2012) observations at the $1.6^{\circ}$ elevation angle (Fig. 8), which captures higher altitudes (i.e., more frozen hydrometeors) than the elevation angle used in sections 3 and 4. HCAs can identify the dominant hydrometeor types in the radar resolution volume, and therefore can be used to evaluate UM's ability to properly simulate hydrometeor fields. The model dominant hydrometeor type is defined as the hydrometeor type that contributes most to linear reflectivity. This allows for a direct comparison of hydrometeor fields between model and observations. The hydrometeor types included in this study are: ground clutter/anomalous propagation (GC/AP), biological scatterers (BS), dry snow/ice crystals (DS/CR), wet snow (WS), rain (RA), rain/rimed ice (RR), and rimed ice (RI). Readers are referred to Putnam et al. (2017) for further details on each method.

Observationally, lower levels of the Changma front are typically composed of rain (Fig. 8a). A melting layer transition region is mostly composed of rain, wet snow, and dry 
snow to the east of the radar. To the south, the transition zone is deeper and consists of two layers: an upper layer with rain, dry snow, wet snow and rimed ice; and a lower layer with rain and rain/rimed ice. Sparse melting is found to the west. Finally, in the upper levels of the radar scan, crystals and dry snow are prominent. Similar to observations, lower levels in the UM are typically composed of rain (Fig. 8b). Model transition regions are primarily composed of rain/rimed ice and wet snow in all directions. Rimed ice is most prominent to the east of the radar domain, but also present to the north and south. In observations, it is typically contained to both the west and south of the radar. This suggests that the model tends to overpredict the presence of graupel compared to observations. The upper levels of the simulated Changma front in the radar domain are typically dry snow/ice crystals, which matches observations well. Still, the presence of rimed ice above the melting layer is greater than in the observations.

Typhoon Sanba (2012) is mostly rain at lower levels (Fig. 8c). This lower-level rain coverage is smaller than that in the Changma front case because of the autumn season. Distinct melting occurs to the west of the radar site, with rain, dry snow and wet snow populating these regions, along with rimed ice. Elsewhere, hydrometeors are typically rain and wet snow in the melting layer. Heights above the melting layer are primarily composed of ice crystals and dry snow. Simulated UM hydrometeors are typically rain at low levels (Fig. 8d), in agreement with the observed predominant hydrometeor type. The melting transition region between frozen and liquid hydrometeors is primarily composed of rimed ice and wet snow in all directions, which is similar to the model Changma case. Model levels above the transition region are primarily composed of dry snow/ice crystals, in agreement with observations. Similar to the Changma case, rimed ice populates upper levels more frequently than observations.

\section{Summary and discussion}

This study examines UM microphysics for two convective cases at $1.5-\mathrm{km}$ grid spacing over the Korean peninsula: a Changma front, and Typhoon Sanba (2012). Simulated polarimetric radar variables are compared to observations from the S-band Biseul-san radar. Clearly, the model struggles with convection, as reflectivity $Z_{\mathrm{H}}$ gaps are present in each case. The consequences of inadequately resolving convection are significant to the model's forecast, as the model is underpredicting precipitation coverage. The diagnostic relation between the rain intercept parameter and mixing ratio results in a rapidly increasing (decreasing) drop size for an increasing (decreasing) mixing ratio. This is partially responsible for the large $Z_{\mathrm{H}}$ gradients present in the cases compared to observations. The ability to correctly predict PSDs in microphysics schemes is potentially important, as they have a significant impact on the evolution of precipitating systems through their feedback to thermodynamics and dynamics. Thus, it is imperative to understand microphysics biases and address them, especially for convective-scale modeling where the microphysics error dominates the forecast errors. Quantitatively, the model generally produces more small and large $Z_{\mathrm{DR}}$ than observations, which is consistent with the diagnostic relationship discussed above. $K_{\mathrm{DP}}$ is less affected by the diagnostic relationship, as it is proportional to a lower order moment than $Z$ and $Z_{\mathrm{DR}}$. Thus, the model drop size bias should be taken into account when interpreting simulated radar variables. The UM's generic ice category, which contains both crystals and snow, overshadowed graupel as the dominant hydrometeor, with neither particle type appreciably reaching the surface. This is reasonable because neither storm system has a strong updraft. Still, graupel might be incorrectly parameterized, as the model graupel is more prominent above the melting level compared to observations.

Many UM microphysics shortcomings in this study stem from the $1 \mathrm{M}$ nature of the scheme. Schemes with $1 \mathrm{M}$ categories have the potential to perform reasonably well for large-scale storm systems (Liu et al., 2011). In that regard, the UM microphysics raindrop size distribution is tuned with aircraft observations collected from stratocumulus and tradewind cumulus (Abel and Boutle, 2012), which may not be adequate for midlatitude deep convective systems where the Korean peninsula is located. As a result, the model struggles with typical mid-latitude weather systems such as the Changma front in this study. An incorrect $N_{0}$ parameterization by many orders of magnitude can adversely affect the rain PSD and its moments, which is directly linked to many microphysical processes. Further, radar variables are sensitive to drop size distributions. For example, radar reflectivity is dependent on drop size to the sixth power, and differential reflectivity is related to the axis ratio of hydrometeors. As radar observations are typically used to monitor severe weather, large biases in simulated radar variables can misguide forecasters as well as introduce large errors in assimilation. A well-calibrated regional rain $N_{0}$ relationship could result in improved model microphysics and forecasts. For improved flexibility and model performance, it is desirable that a $2 \mathrm{M}$ version of the UM microphysics scheme be developed. As an example, the $2 \mathrm{M}$ version would potentially be able to simulate both heavy rain dominated by small drops with relatively uniform size in warm-rain processes, and heavy rain with many large raindrops in cold-rain processes. While adjusting the rain $N_{0}$ configuration for different weather systems could mitigate this problem to some degree, evolving the scheme to $2 \mathrm{M}$ would allow more freedom to simulate a wider range of weather systems.

Acknowledgements. This research was supported by a research grant of "Development of a Polarimetric Radar Data Simulator for Local Forecasting Model (II)" by the KMA. Further support was provided by a NOAA Warn-on-Forecast grant (Grant No. NA16OAR4320115) and a National Science Foundation grant (Grant No. AGS-1261776). We also thank the two anonymous reviewers for their help in improving the quality of this manuscript.

Open Access. This article is distributed under the terms of the Creative Commons Attribution License which permits any use, distribution, and reproduction in any medium, provided the original 
author(s) and the source are credited.

\section{REFERENCES}

Abel, S. J., and I. A. Boutle, 2012: An improved representation of the raindrop size distribution for single-moment microphysics schemes. Quart. J. Roy. Meteor. Soc., 138, 21512162, https://doi.org/10.1002/qj.1949.

Ballard, S. P., Z. H. Li, D. Simonin, and J.-F. Caron, 2016: Performance of 4D-var NWP-based nowcasting of precipitation at the met office for summer 2012. Quart. J. Roy. Meteor. Soc., 142, 472-487, https://doi.org/10.1002/qj.2665.

Brown, B. R., M. M. Bell, and A. J. Frambach, 2016: Validation of simulated hurricane drop size distributions using polarimetric radar. Geophys. Res. Lett., 43, 910-917, https://doi.org/ 10.1002/2015GL067278.

Bryan, G. H., and H. Morrison, 2012: Sensitivity of a simulated squall line to horizontal resolution and parameterization of microphysics. Mon. Wea. Rev., 140, 202-225, https://doi.org/ 10.1175/MWR-D-11-00046.1.

Cintineo, R., J. A. Otkin, M. Xue, and F. Y. Kong, 2014: Evaluating the performance of planetary boundary layer and cloud microphysical parameterization schemes in convectionpermitting ensemble forecasts using synthetic GOES-13 satellite observations. Mon. Wea. Rev., 142, 163-182, https:// doi.org/10.1175/MWR-D-13-00143.1.

Dawson, D. T., M. Xue, J. A. Milbrandt, and M. K. Yau, 2010: Comparison of evaporation and cold pool development between single-moment and multimoment bulk microphysics schemes in idealized simulations of tornadic thunderstorms. Mon. Wea. Rev., 138, 1152-1171, https://doi.org/10.1175/ 2009MWR2956.1.

Dawson, D. T., L. J. Wicker, E. R. Mansell, Y. Jung, and M. Xue, 2013: Low-level polarimetric radar signatures in EnKF analyses and forecasts of the May 8, 2003 Oklahoma City tornadic supercell: Impact of multimoment microphysics and comparisons with observation. Advances in Meteorology, 2013, 818394, https://doi.org/10.1155/2013/818394.

Dawson, D. T., E. R. Mansell, Y. Jung, L. J. Wicker, M. R. Kumjian, and M. Xue, 2014: Low-level $Z_{\mathrm{DR}}$ signatures in supercell forward flanks: The role of size sorting and melting of hail. J. Atmos. Sci., 71, 276-299, https://doi.org/10.1175/JASD-13-0118.1.

Field, P. R., A. J. Heymsfield, and A. Bansemer, 2007: Snow size distribution parameterization for midlatitude and tropical ice clouds. J. Atmos. Sci., 64, 4346-4365, https://doi.org/ 10.1175/2007JAS2344.1.

Field, P. R., R. J. Hogan, P. R. A. Brown, A. J. Illingworth, T. W. Choularton, and R. J. Cotton, 2005: Parametrization of iceparticle size distributions for mid-latitude stratiform cloud. Quart. J. Roy. Meteor. Soc., 131, 1997-2017, https://doi.org/ 10.1256/qj.04.134.

Goldenberg, S. B., S. G. Gopalakrishnan, V. Tallapragada, T. Quirino, F. Marks Jr., S. Trahan, X. J. Zhang, and R. Atlas, 2015: The 2012 triply nested, high-resolution operational version of the hurricane weather research and forecasting model (HWRF): Track and intensity forecast verifications. Wea. Forecasting, 30, 710-729, https://doi.org/10.1175/WAF-D14-00098.1.

Hanley, K. E., R. S. Plant, T. H. M. Stein, R. J. Hogan, J. C. Nicol, H. W. Lean, C. Halliwell, and P. A. Clark, 2015: Mixing- length controls on high-resolution simulations of convective storms. Quart. J. Roy. Meteor. Soc., 141, 272-284, https:// doi.org/10.1002/qj.2356.

Hong, S.-Y., and J.-O. J. Lim, 2006: The WRF single-moment 6class microphysics scheme (WSM6). Korean Meteorological Society, 42, 129-151.

Houze, R. A., Jr., 2010: Clouds in tropical cyclones. Mon. Wea. Rev., 138, 293-344, https://doi.org/10.1175/2009MWR2989. 1.

Johnson, M., Y. Jung, D. T. Dawson II, and M. Xue, 2016: Comparison of simulated polarimetric signatures in idealized supercell storms using two-moment bulk microphysics schemes in WRF. Mon. Wea. Rev., 144, 971-996, https://doi.org/ 10.1175/MWR-D-15-0233.1.

Jung, Y., G. F. Zhang, and M. Xue, 2008: Assimilation of simulated polarimetric radar data for a convective storm using the ensemble Kalman filter. Part I: Observation operators for reflectivity and polarimetric variables. Mon. Wea. Rev., 136, 2228-2245, https://doi.org/10.1175/2007MWR2083.1.

Jung, Y., M. Xue, and G. F. Zhang, 2010: Simulations of polarimetric radar signatures of a supercell storm using a two-moment bulk microphysics scheme. Journal of Applied Meteorology and Climatology, 49, 146-163, https://doi.org/10.1175/ 2009JAMC2178.1.

Jung, Y., M. Xue, and M. J. Tong, 2012: Ensemble Kalman filter analyses of the 29-30 May 2004 Oklahoma tornadic thunderstorm using one- and two-moment bulk microphysics schemes, with verification against polarimetric radar data. Mon. Wea. Rev., 140, 1457-1475, https://doi.org/10.1175/ MWR-D-11-00032.1.

Kim, D.-J., 2015: Center report from KMA-forecasting system operation \& research. WGNE-30.

Lin, Y.-L., R. D. Farley, and H. D. Orville, 1983: Bulk parameterization of the snow field in a cloud model. J. Appl. Meteor., 22, 1065-1092, https://doi.org/10.1175/1520-0450 (1983)022<1065:BPOTSF $>2.0 . C O ; 2$.

Liu, C. H., K. Ikeda, G. Thompson, R. Rasmussen, and J. Dudhia, 2011: High-resolution simulations of wintertime precipitation in the Colorado Headwaters region: Sensitivity to physics parameterizations. Mon. Wea. Rev., 139, 3533-3553, https://doi.org/10.1175/MWR-D-11-00009.1.

Mansell, E. R., C. L. Ziegler, and E. C. Bruning, 2010: Simulated electrification of a small thunderstorm with two-moment bulk microphysics. J. Atmos. Sci., 67, 171-194, https://doi.org/ 10.1175/2009JAS2965.1.

McMillen, J. D., and W. J. Steenburgh, 2015: Impact of microphysics parameterizations on simulations of the 27 October 2010 Great Salt Lake-effect snowstorm. Wea. Forecasting, 30, 136-152, https://doi.org/10.1175/WAF-D-14-00060.1.

Milbrandt, J. A., and M. K. Yau, 2005: A multimoment bulk microphysics parameterization. Part II: A proposed threemoment closure and scheme description. J. Atmos. Sci., 62, 3065-3081, https://doi.org/10.1175/JAS3535.1.

Milbrandt, J. A., and M. K. Yau, 2006: A multimoment bulk microphysics parameterization. Part IV: Sensitivity experiments. J. Atmos. Sci., 63, 3137-3159, https://doi.org/10.1175/ JAS3817.1.

Morrison, H., and J. Milbrandt, 2011: Comparison of two-moment bulk microphysics schemes in idealized supercell thunderstorm simulations. Mon. Wea. Rev., 139, 1103-1130, https:// doi.org/10.1175/2010MWR3433.1.

Morrison, H., G. Thompson, and V. Tatarskii, 2009: Impact of 
cloud microphysics on the development of trailing stratiform precipitation in a simulated squall line: Comparison of oneand two-moment schemes. Mon. Wea. Rev., 137, 991-1007, https://doi.org/10.1175/2008MWR2556.1.

Morrison, H., S. A. Tessendorf, K. Ikeda, and G. Thompson, 2012: Sensitivity of a simulated midlatitude squall line to parameterization of raindrop breakup. Mon. Wea. Rev., 140, 24372460, https://doi.org/10.1175/MWR-D-11-00283.1.

Morrison, H., J. A. Milbrandt, G. H. Bryan, K. Ikeda, S. A. Tessendorf, and G. Thompson, 2015: Parameterization of cloud microphysics based on the prediction of bulk ice particle properties. Part II: Case study comparisons with observations and other schemes. J. Atmos. Sci., 72, 312-339, https:// doi.org/10.1175/JAS-D-14-0066.1.

Nicol, J. C., R. J. Hogan, T. H. M. Stein, K. E. Hanley, P. A. Clark, C. E. Halliwell, H. W. Lean, and R. S. Plant, 2015: Convective updraught evaluation in high-resolution NWP simulations using single-Doppler radar measurements. Quart. J. Ror. Meteor. Soc., 141, 3177-3189, https://doi.org/10.1002/ qj.2602.

Pan, Y. J., M. Xue, and G. Q. Ge, 2016: Incorporating diagnosed intercept parameters and the graupel category within the ARPS cloud analysis system for the initialization of double-moment microphysics: Testing with a squall line over South China. Mon. Wea. Rev., 144, 371-392, https://doi.org/ 10.1175/MWR-D-15-0008.1.

Park, H. S., A. V. Ryzhkov, D. S. Zrnić, and K.-E. Kim, 2009: The hydrometeor classification algorithm for the polarimetric WSR-88D: Description and application to an MCS. Wea. Forecasting, 24, 730-748, https://doi.org/10.1175/2008 WAF2222205.1.

Park, J.-S., Y. H. Lee, M. Suk, K. Nam, Y. Jung, and J. Ko, 2015a: Evaluation of UM microphysics using dual-polarised radar simulator. Proceedings of the 37th Conference on Radar Meteorology, Norman, OK, American Meteorological Society.

Park, S., S.-H. Jung, and G. Lee, 2015b: Cross validation of TRMM PR reflectivity profiles using 3D reflectivity composite from the ground-based radar network over the Korean peninsula. Journal of Hydrometeorology, 16, 668-687, https://doi.org/10.1175/JHM-D-14-0092.1.

Potvin, C. K., and M. L. Flora, 2015: Sensitivity of idealized supercell simulations to horizontal grid spacing: Implications for warn-on-forecast. Mon. Wea. Rev., 143, 2998-3024, https://doi.org/10.1175/MWR-D-14-00416.1.

Putnam, B. J., M. Xue, Y. Jung, G. F. Zhang, and F. Y. Kong, 2017: Simulation of polarimetric radar variables from 2013 CAPS spring experiment storm-scale ensemble forecasts and evaluation of microphysics schemes. Mon. Wea. Rev., 145, 49-73, https://doi.org/10.1175/MWR-D-15-0415.1.

Rutledge, S. A., and P. V. Hobbs, 1983: The mesoscale and microscale structure and organization of clouds and precipitation in midlatitude cyclones. VIII: A model for the "seeder-feeder" process in warm-frontal rainbands. J. Atmos. Sci., 40, 1185-1206, https://doi.org/10.1175/1520-0469 (1983) $040<1185$ :TMAMSA > 2.0.CO;2.

Straka, J. M., M. S. Gilmore, K. M. Kanak, and E. N. Rasmussen, 2005: A comparison of the conservation of number concentration for the continuous collection and vapor diffu- sion growth equations using one- and two-moment schemes. J. Appl. Meteor., 44, 1844-1849, https://doi.org/10.1175/ JAM2314.1.

Tang, Y. M., H. W. Lean, and J. Bornemann, 2013: The benefits of the Met Office variable resolution NWP model for forecasting convection. Meteorological Applications, 20, 417-426, https://doi.org/10.1002/met.1300.

Tao, W.-K., and J. Simpson, 1993: Goddard cumulus ensemble model. Part I: Model description. TAO, 4, 35-72, https://doi. org/10.3319/TAO.1993.4.1.35(A).

Thompson, G., P. R. Field, R. M. Rasmussen, and W. D. Hall, 2008: Explicit forecasts of winter precipitation using an improved bulk microphysics scheme. Part II: Implementation of a new snow parameterization. Mon. Wea. Rev., 136, 50955115, https://doi.org/10.1175/2008MWR2387.1.

Van Weverberg, K., N. P. M. Van Lipzig, and L. Delobbe, 2011: The impact of size distribution assumptions in a bulk one-moment microphysics scheme on simulated surface precipitation and storm dynamics during a low-topped supercell case in Belgium. Mon. Wea. Rev., 139, 1131-1147, https://doi.org/10.1175/2010MWR3481.1.

Van Weverberg, K., A. M. Vogelmann, H. Morrison, and J. A. Milbrandt, 2012: Sensitivity of idealized squall-line simulations to the level of complexity used in two-moment bulk microphysics schemes. Mon. Wea. Rev., 140, 1883-1907, https://doi.org/10.1175/MWR-D-11-00120.1.

Verrelle, A., D. Ricard, and C. Lac, 2015: Sensitivity of highresolution idealized simulations of thunderstorms to horizontal resolution and turbulence parametrization. Quart. J. Roy. Meteor. Soc., 141, 433-448, https://doi.org/10.1002/qj.2363.

Wainwright, C. E., D. T. Dawson II, M. Xue, and G. F. Zhang, 2014: Diagnosing the intercept parameters of the exponential drop size distributions in a single-moment microphysics scheme and impact on supercell storm simulations. J. Appl. Meteor. Climatol., 53, 2072-2090, https://doi.org/ 10.1175/JAMC-D-13-0251.1.

Weisman, M. L., W. C. Skamarock, and J. B. Klemp, 1997: The resolution dependence of explicitly modeled convective systems. Mon. Wea. Rev., 125, 527-548, https://doi.org/10.1175/ 1520-0493(1997)125<0527:TRDOEM>2.0.CO;2.

Wilkinson, J. M., A. N. F. Porson, F. J. Bornemann, M. Weeks, P. R. Field, and A. P. Lock, 2013: Improved microphysical parametrization of drizzle and fog for operational forecasting using the Met Office Unified Model. Quart. J. Roy. Meteor. Soc., 139, 488-500, https://doi.org/10.1002/qj.1975.

Wilson, D. R., and S. P. Ballard, 1999: A microphysically based precipitation scheme for the UK meteorological office unified model. Quart. J. Roy. Meteor. Soc., 125, 1607-1636, https:// doi.org/10.1002/qj.49712555707.

Zhang, G., J. Vivekanandan, and E. Brandes, 2001: A method for estimating rain rate and drop size distribution from polarimetric radar measurements. IEEE Trans. Geosci. Remote Sens., 39, 830-841, https://doi.org/10.1109/36.917906.

Zhang, G. F., M. Xue, Q. Cao, and D. Dawson, 2008: Diagnosing the intercept parameter for exponential raindrop size distribution based on video disdrometer observations: Model development. J. Appl. Meteor. Climatol., 47, 2983-2992, https:// doi.org/10.1175/2008JAMC1876.1. 